\title{
Radioiodination of surface proteins of bull spermatozoa and their characterization by sodium dodecyl sulphate- polyacrylamide gel electrophoresis
}

\author{
M. Vierula and H. Rajaniemi* \\ Department of Anatomy, University of Kuopio, 70101 Kuopio 10, and *Department of Anatomy, \\ University of Oulu, 90220 Oulu 22, Finland
}

\begin{abstract}
Summary. Surface proteins of ejaculated bull spermatozoa were radioiodinated, solubilized and characterized by sodium dodecyl sulphate-polyacrylamide gel electrophoresis. The electron microscopic autoradiographs showed that the labelling was equally distributed to all parts of the spermatozoon and restricted to the sperm surface. The electrophoresis of solubilized radioactivity revealed 6 radioactive fractions with approximate molecular weights of 67000-69000, 47 000-50 000, $34000-37000,25000-28000$, and 14000-16000. The 6th fraction probably represented labelled lipids. The electrophoresis of radioiodinated seminal plasma proteins revealed only 2 radioactive protein peaks which coincided with the sperm surface protein fractions IV and V.
\end{abstract}

\section{Introduction}

The outer surface of the spermatozoon has been the subject of intensive investigation during the past few years. These studies have clearly indicated that the composition of the mammalian sperm surface undergoes molecular changes during epididymal transit and capacitation and that these changes are necessary for the spermatozoa to achieve fertilizing ability. The approaches used to investigate these macromolecular changes on the sperm surface have been numerous. The density and distribution of negative charges have been investigated at various developmental stages by means of a colloidal iron hydroxide labelling technique (Cooper \& Bedford, 1971; Yanagimachi, Noda, Fujimoto \& Nicolson, 1972; Bedford, Cooper \& Calvin, 1972; Yanagimachi, Nicolson, Noda \& Fujimoto, 1973; Fléchon, 1975). However, this technique gives only limited information of the chemical nature of the binding sites of colloidal iron hydroxide.

The distribution of glycoproteins on the sperm surface has been studied by using carbohydrate-specific lectins (Edelman \& Millette, 1971; Nicolson \& Yanagimachi, 1972; Nicolson \& Yanagimachi, 1974; Gordon, Dandekar \& Bartoszewicz, 1974, 1975; Nicolson, Usui, Yanagimachi, Yanagimachi \& Smith, 1977). Olson \& Hamilton (1978) labelled the surface carbohydrate residues of rat spermatozoa from the caput and cauda epididymidis by a galactose oxidase-sodium $\left[{ }^{3} \mathrm{H}\right]$ borohydride or sodium metaperiodate-sodium $\left[{ }^{3} \mathrm{H}\right]$ borohydride technique.

The surface composition of spermatozoa has not been analysed by using protein-specific biochemical probes. Lactoperoxidase-catalysed radioiodination has been successfully used to label tyrosine (and probably histidine) residues of soluble proteins (Marchalonis, 1969), but when this method was applied to intact human erythrocytes, haemoglobin was not labelled, indicating that lactoperoxidase could not penetrate the erythrocyte membrane (Phillips \& Morrison, 1970). Marchalonis, Cone \& Santer (1971) radioiodinated the surface proteins of mouse lymphocytes 
in a single-cell suspension and also found that in electron microscopic autoradiographs the grains were associated only with the outer surfaces of the intact cells.

In this study we used the lactoperoxidase-catalysed radioiodination technique to label tyrosine-containing proteins and glycoproteins on the surface of ejaculated bull spermatozoa.

\section{Materials and Methods}

\section{Semen collection and washing of spermatozoa}

Spermatozoa were obtained from Finnish Ayrshire bulls by means of an artificial vagina. Semen samples were transported immediately after collection to the laboratory. Only samples in which the average concentration of spermatozoa was $1000-2000 \times 10^{6} / \mathrm{ml}$ and the motility was $>60 \%$ were accepted for radioiodination. The labelling of spermatozoa was always performed within $6 \mathrm{~h}$ after collection.

An aliquot of $1 \mathrm{ml}$ semen was diluted in $2 \mathrm{ml}$ sperm-Ringer solution, $\mathrm{pH} 7.4$ (Mann, 1946). The spermatozoa were then washed in a saline-based medium containing $7.5 \%$ Ficoll (Pharmacia, Uppsala, Sweden) according to the procedure described by Harrison (1976). After centrifugation through Ficoll the spermatozoa were washed in sperm-Ringer solution (pH 7.0) by centrifugation at $500 \mathrm{~g}$ for $10 \mathrm{~min}$ to remove Ficoll. The final sperm pellet was resuspended in

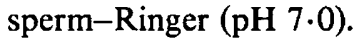

\section{Radioiodination of the surface proteins of spermatozoa}

The lactoperoxidase-catalysed radioiodination procedure was used essentially as described by Marchalonis et al. (1971). The iodination was carried out at room temperature and the reaction mixture contained 300-600 $\times 10^{6}$ spermatozoa, $20 \mu \mathrm{g}$ (2.44 i.u.) lactoperoxidase (Calbiochem, San Diego, California; grade B), $0.5 \mathrm{mCi}$ carrier-free $\mathrm{Na}^{125}$ (Radiochemical Centre, Amersham, England) in total volume of $1 \mathrm{ml}$ sperm-Ringer solution ( $\mathrm{pH} \mathrm{7.0)}$. The iodination reaction was initiated and sustained by adding three $20 \mu \mathrm{l}$ aliquots of $88 \mu \mathrm{M}$-hydrogen peroxide at $5 \mathrm{~min}$ intervals. The reaction was allowed to proceed for $15 \mathrm{~min}$ and thereafter stopped by adding $4 \mathrm{ml} 1 \mathrm{~mm}-\mathrm{NaI}$ prepared in sperm-Ringer solution. Labelled spermatozoa were then sedimented by centrifugation at $500 \mathrm{~g}$ for $10 \mathrm{~min}$ at $22^{\circ} \mathrm{C}$ and washed 4 times in $5 \mathrm{ml} \mathrm{sperm}$ Ringer solution ( $\mathrm{pH} \mathrm{7.4)}$ ). The final sperm pellet was suspended in $1 \mathrm{ml}$ sperm-Ringer solution $\left(\mathrm{pH} \mathrm{7.4)}\right.$ and the suspension was divided into aliquots of $250 \mu \mathrm{l}$, frozen and stored at $-80^{\circ} \mathrm{C}$ until electrophoretic analysis. The morphology and motility of the spermatozoa were studied immediately after iodination and in the final suspension after washing.

For electron microscopic autoradiography the spermatozoa were radioiodinated identically.

\section{Radioiodination of seminal plasma proteins}

Semen diluted in sperm-Ringer $(1: 2 \mathrm{v} / \mathrm{v})$ was centrifuged at $1200 \mathrm{~g}$ for $45 \mathrm{~min}$ at $4{ }^{\circ} \mathrm{C}$. The reaction mixture contained $100 \mu \mathrm{l}$ seminal supernatant, $20 \mu \mathrm{g}$ lactoperoxidase and $0.2 \mathrm{mCi}$ carrier-free $\mathrm{Na}^{125} \mathrm{I}$ in a total volume of $1 \mathrm{ml}$ sperm-Ringer solution $(\mathrm{pH} 7.0$ ). The iodination reaction was initiated and sustained by adding three $20 \mu \mathrm{l}$ aliquots of $88 \mu \mathrm{M}$-hydrogen peroxide at $5 \mathrm{~min}$ intervals. After incubation for $15 \mathrm{~min}$ the reaction was terminated by adding $2 \mathrm{ml}$ sperm-Ringer solution ( $\mathrm{pH} \mathrm{7.4).} \mathrm{The} \mathrm{reaction} \mathrm{mixture} \mathrm{was} \mathrm{then} \mathrm{divided} \mathrm{into} \mathrm{aliquots} \mathrm{of} 250 \mu \mathrm{l}$, frozen and stored at $-80^{\circ} \mathrm{C}$ until analysed by electrophoresis.

\section{Electron microscopic autoradiography}

Labelled spermatozoa were fixed in PFG-cacodylate, which contained $11 \%$ picric acid, $1 \%$ formaldehyde, $1.25 \%$ glutaraldehyde and $150 \mathrm{~mm}$-sodium cacodylate prepared as described by 
Ito \& Karnovsky (1968) and postfixed in osmium-cacodylate containing $40 \mathrm{~mm}$-osmium tetroxide, $75 \mathrm{~mm}$-glucose and $150 \mathrm{~mm}$-sodium cacodylate following the procedure described by Jones (1973). After fixation the spermatozoa were centrifuged at $1200 \mathrm{~g}$ for $30 \mathrm{~min}$ and the pellet was then cut into small pieces, which were dehydrated in ethanol and propylene oxide and embedded in Epon 812. Ultrathin sections, silver or gray, were cut and stained with uranyl acetate and lead citrate for $30 \mathrm{~min}$ and $5 \mathrm{~min}$ respectively. The sections were processed for autoradiography by the loop method described by Caro \& Van Tubergen (1962) using Ilford $\mathrm{L}_{4}$ emulsion (Ilford Limited, Ilford, Essex, England). The samples were exposed for 4 weeks and developed with Kodak Microdol-X for $5 \mathrm{~min}$ and fixed with Ilford Hypam for $5 \mathrm{~min}$ at $20^{\circ} \mathrm{C}$. The specimens were examined in a Jeol $100 \mathrm{~B}$ electron microscope.

The distribution of the grains in relation to the plasma membrane was analysed by measuring the distances of the grain centres from it in HD units (Salpeter, McHenry \& Salpeter, 1978). The half distance (HD) for ${ }^{125} \mathrm{I}$ when Ilford $L_{4}$ nuclear emulsion is used is $90 \mathrm{~nm}$ (Salpeter et al., 1978). The centre of the grain, determined by punching the centre of the smallest possible circle around the grain was considered as the location of the grain. Forty-six micrographs were analysed and 400 grains were counted.

\section{Disc electrophoresis}

Polyacrylamide gel electrophoresis in sodium dodecyl sulphate (SDS)-containing gels (10\% acrylamide, $0.37 \% \mathrm{~N}, \mathrm{~N}^{\prime \prime}$ methylene-bis-acrylamide, $0.1 \% \mathrm{SDS}$ ) was performed according to the method of Zahler (1974). Labelled sperm suspension $(250 \mu \mathrm{l})$ was diluted to $0.5 \mathrm{ml}$ so that the final concentrations of SDS, urea and $\beta$-mercaptoethanol in the sample were $1 \%, 4 \mathrm{M}$, and $1 \%$ respectively. The sample suspension was heated at $100^{\circ} \mathrm{C}$ for $4 \mathrm{~min}$ and then centrifuged at $20000 \mathrm{~g}$ for $30 \mathrm{~min}$. Aliquots of $30-50 \mu$ of the supernatant were layered on to polyacrylamide gels $(0.5 \times 9.5 \mathrm{~cm})$. Pyronine-Y was used as the marker stain. Running buffer contained $0.1 \%$ SDS in $0.1 \mathrm{M}$-sodium phosphate ( $\mathrm{pH} \mathrm{7.0)}$. After running for $11 \mathrm{~h}(5 \mathrm{~mA} / \mathrm{gel})$ at room temperature the gels were removed from the tubes and frozen in a freezing box. The frozen gels were sliced into $1 \mathrm{~mm}$ sections, which were counted for ${ }^{125} \mathrm{I}$ radioactivity (efficiency for ${ }^{125} \mathrm{I}, 52 \%$ ).

The standard proteins included in the electrophoreses were bovine serum albumin (mol. wt 68000 ), ovalbumin (mol. wt 45000 ), chymotrypsinogen A (mol. wt. 25000 ), and cytochrome c (mol. wt 12 500) (Combithek; Boehringer Mannheim GmbH, Western Germany). The approximate molecular weights of labelled surface proteins were estimated from their respective relative mobilities.

Some gels were also stained with Coomassie Brilliant Blue for proteins.

\section{Results}

\section{Radioiodination of spermatozoa and localization of radioactivity}

The morphological integrity and motility of bull spermatozoa was preserved well during the iodination and subsequent washings. Immediately after termination of the iodination the spermatozoa were morphologically intact (P1. 1, Fig. 1) and $20-30 \%$ of them were still motile at room temperature. After the subsequent washings some loose heads and tails appeared but over $90 \%$ of the washed spermatozoa were morphologically intact (Pl. 1, Fig. 2). The average radioactivity in the final labelled sperm suspension was 3-4 $410^{6}$ c.p.m. $/ 300-600 \times 10^{6}$ spermatozoa. The electron microscope autoradiographs showed that the grains of the iodine label were mostly associated with the plasma membrane and that they were equally distributed to every part of the spermatozoon (PI. 1, Figs 3-6).

The grain distribution analysed in relation to the plasma membrane is shown in Text-fig. 1 . The distribution fits very well with that expected for a radioactive line source. The grain counting showed that $68 \%$ of the grains were located within $2 \mathrm{HD}$ units of the plasma membrane. 


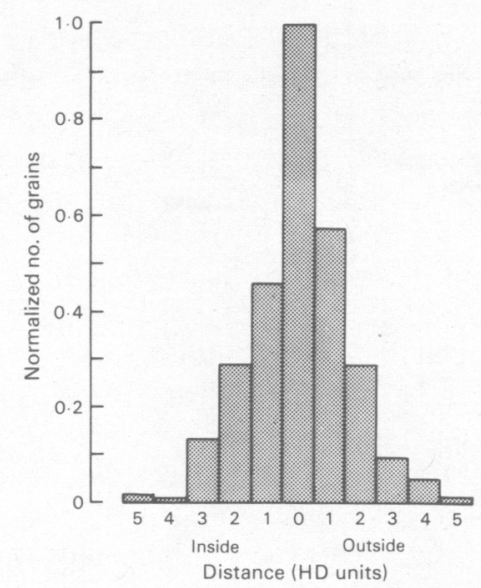

Text-fig. 1. Histogram of the grain distribution analysed in relation to the plasma membrane of the spermatozoa.

\section{Fractionation of radioiodinated surface proteins of spermatozoa}

To analyse the molecular composition of the labelled surface proteins the sperm samples (7$10 \times 10^{5}$ c.p.m.) were solubilized and fractionated by SDS-polyacrylamide gel electrophoresis. Heating the sperm suspension in SDS, urea and $\beta$-mercaptoethanol solution effectively solubilized the spermatozoa and only nuclei could be identified by phase-contrast microscopy after the treatment. The nuclei were pelleted by centrifugation and the supernatant, which contained over $85 \%$ of the total radioactivity in the sample, was subjected to electrophoresis. Several acrylamide concentrations ranging from 5 to $15 \%$ were tested. The best separation of radioactive proteins was achieved with $10 \%$ polyacrylamide gels containing $0 \cdot 1 \%$ SDS. The electrophoresis repeatably revealed 6 radioactive peaks (Text-fig. 2a). The $R_{\mathrm{F}}$ values and approximate molecular weights of the first 5 peaks (I-V) are presented in Table 1. Sperm

Table 1. The approximate $R_{\mathrm{F}}$ values and molecular weights of the first 5 labelled surface proteins of bull spermatozoa separated by SDS-polyacrylamide gel electrophoresis

\begin{tabular}{ccc}
\hline Proteins & $R_{F}$ values & Molecular weights \\
\hline I & $0 \cdot 09-0 \cdot 10$ & $67000-69000$ \\
II & $0 \cdot 17-0.20$ & $47000-50000$ \\
III & $0 \cdot 30-0.34$ & $34000-37000$ \\
IV & $0.40-0.45$ & $25000-28000$ \\
V & $0.64-0.69$ & $14000-16000$ \\
\hline
\end{tabular}

\section{PLATE 1}

Fig. 1. Spermatozoa immediately after radioiodination. Incubation of the reaction mixture did not cause any morphological damage to the spermatozoa. $\times 1000$.

Fig. 2. Labelled and washed spermatozoa in the final suspension. Some loose heads and tails were present, but the majority of spermatozoa were still intact. $\times 1000$.

Figs 3-6. Electron microscopic autoradiographs prepared from the radioiodinated spermatozoa show that the grains are associated mostly with the plasma membrane in every part of the spermatozoon. $\times 11500$. 
PLATE 1
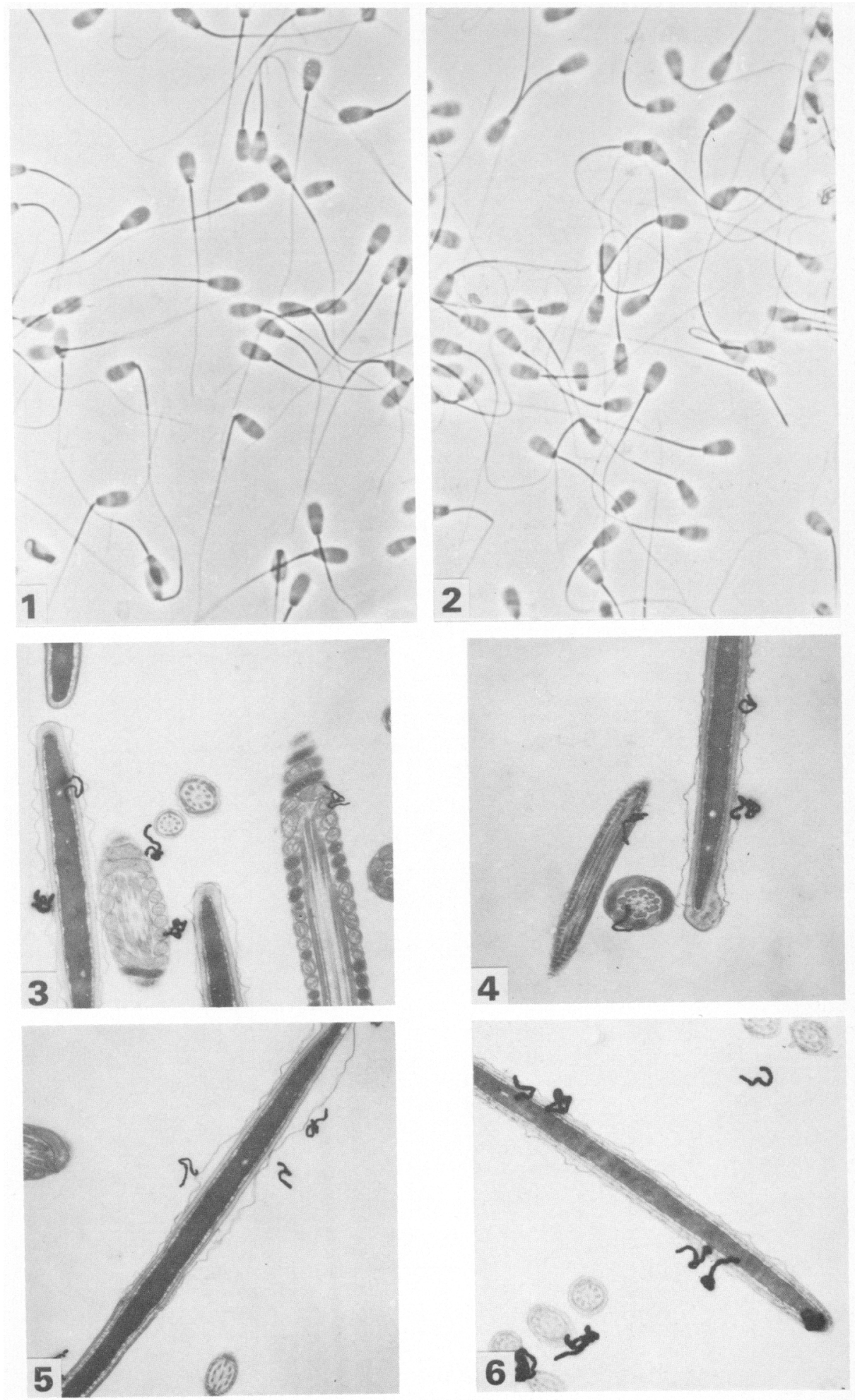

(Facing p. 486) 

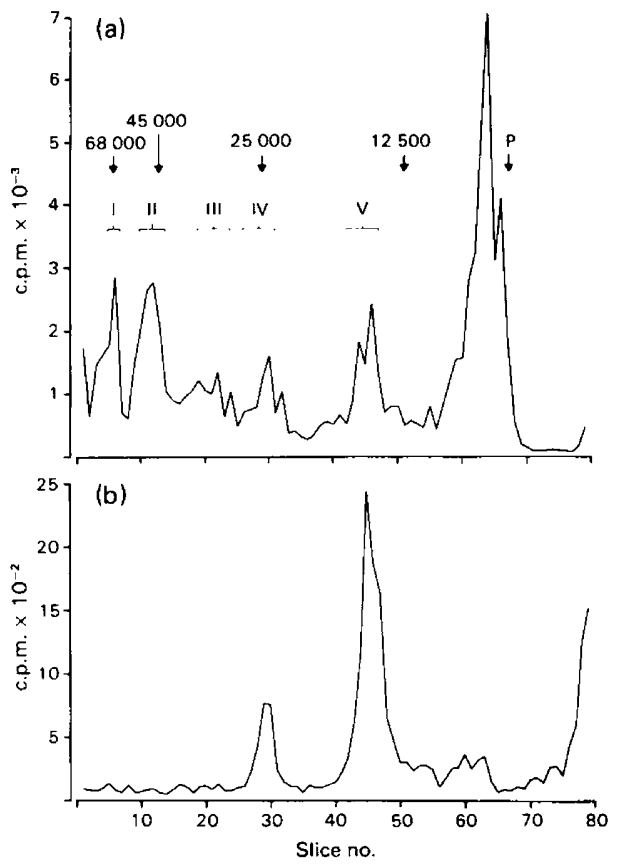

Text-fig. 2. Distribution of radioactivity of the labelled spermatozoa (a) and seminal plasma (b) of the same bull in SDS-polyacrylamide gel electrophoresis. The localization of standard proteins with known molecular weights (see 'Methods') and pyronine-Y (P) are shown. The usual positions of the first 5 labelled protein fractions (I-V) are indicated.

samples from 15 different bulls have been labelled and virtually the same radioactive peaks have been repeatably obtained, within and amongst bulls (Text-fig. 3). Coomassie Brilliant Blue staining displayed at least 15 protein bands with $R_{\mathrm{F}}$ values between 0.02 and 0.75 and molecular weights between 100000 and 12000 .

\section{Fractionation of the radioiodinated seminal plasma proteins}

The proteins labelled in the seminal plasma were distributed between two peaks with approximate molecular weights of 25000-28 000 and 14000-16000 (Text-fig. 2b), which seemed to coincide with peaks IV and V of the sperm surface proteins (Text-fig. 2a).

\section{Discussion}

The present results show that spermatozoa, like erythrocytes (Phillips \& Morrison, 1970) and lymphocytes (Marchalonis et al., 1971), can be labelled by lactoperoxidase-catalysed radioiodination. Analysis of the grain distribution over the spermatozoa in relation to the plasma membrane showed that most of the grains were associated with the plasma membrane, suggesting that the radioiodine label is located at the surface of the spermatozoon. Although the distribution of the radioactive labelling in the SDS-electrophoresis was consistent within and among bulls, fractions often showed two or more subpeaks, indicating that each probably consists of more than one protein component. The 6th peak of radioactivity moved near the tracking dye and probably represented labelled membrane lipids (Mersel, Benenson \& Doljanski, 1976).

The electrophoresis of labelled seminal plasma displayed two fractions of radioactivity which 


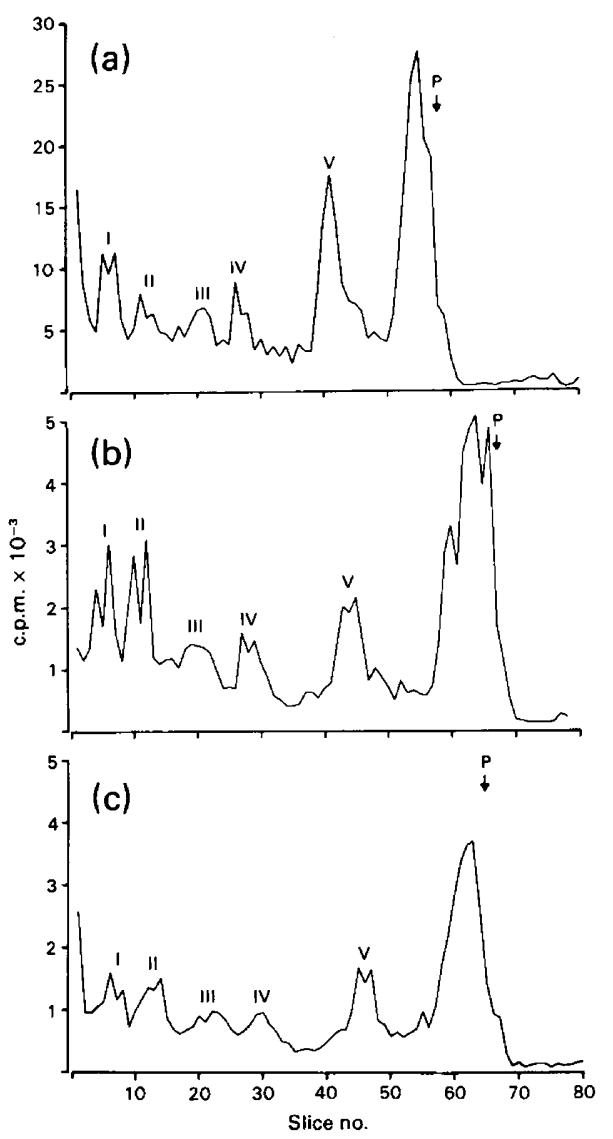

Text-fig. 3. Distribution of radioactivity of the labelled spermatozoa from 3 different bulls. The main protein fractions (I-V) in each sample are identified. The sample volumes applied were 50 $\mu \mathrm{l}$ for (a) and $30 \mu \mathrm{l}$ for (b) and (c). The radioactivity in (a) was higher than that in the other two samples.

coincided with the fractions IV and V of the spermatozoa. This observation suggests that the surface of ejaculated bull spermatozoa and seminal plasma may have some protein components in common. This is further evidence for the fact that there may be an interaction between the surface of the spermatozoon and surrounding seminal plasma proteins (Voglmayr, Fairbanks, Jackowitz \& Colella, 1979). The functional significance of the labelled surface proteins detected by SDS-electrophoresis remains to be elucidated. However, some may play a role in the development of the fertilizing capacity of the spermatozoa during their maturation process in the accessory sex organs. Olson \& Hamilton (1978) have shown that a new glycoprotein appears on the sperm surface during transit through the epididymis and the technique of radioiodination of intact spermatozoa can now be used to characterize the protein structure of the sperm surface and its changes at different developmental stages.

We thank Dr Eero Remes for arranging the bull semen samples; and Miss Arja Venäläinen and Miss Sirkka Pennanen for expert technical and secretarial assistance. This work was supported by grants from The Cultural Foundation of Finland and The Academy of Finland, The Finnish Medical Council. 


\section{References}

Bedford, J.M., Cooper, G.W. \& Calvin, H.I. (1972) Postmeiotic changes in the nucleus and membranes of mammalian spermatozoa. In The Genetics of the Spermatozoon, pp. 69-89. Eds R. A. Beatty \& S. Gluecksohn-Waelsh. Beatty \& Gluecksohn-Waelsh, Edinburgh.

Caro, L.G. \& Van Tubergen, R.P. (1962) High resolution autoradiography. I. Methods. J. Cell Biol. 15, 173-188.

Cooper, G.W. \& Bedford, J.M. (1971) Acquisition of surface charge by the plasma membrane of mammalian spermatozoa during epididymal maturation. Anat. Rec. 169, 300-301, Abstr.

Edeiman, G.M. \& Millette, C.F. (1971) Molecular probes of spermatozoan structures. Proc. natn. Acad. Sci. U.S.A. 68, 2436-2440.

Fléchon, J.E. (1975) Ultrastructural and cytochemical modifications of rabbit spermatozoa during epididymal transport. In The Biology of Spermatozoa, pp. 36-45. Eds E. S. E. Hafez \& C. G. Thibault. S. Karger, Basel.

Gordon, M., Dandekar, P.V. \& Bartoszewicz, W. (1974) Ultrastructural localization of surface receptors for Concanavalin A on rabbit spermatozoa. J. Reprod. Fert. 36, 211-214.

Gordon, M., Dandekar, P.V. \& Bartoszewicz, W. (1975) The surface coat of epididymal, ejaculated and capacitated sperm. J. Ultrastruct. Res. 50, 199-207.

Harrison, R.A.P. (1976) A highly efficient method for washing mammalian spermatozoa. J. Reprod. Fert. 48, 347-353.

Ito, S. \& Karnovsky, M.J. (1968) Formaldehydeglutaraldehyde fixatives containing trinitro compounds. J. Cell Biol. 39, 168a-169a, Abstr.

Jones, R.C. (1973) Preparation of spermatozoa for electron and light microscopy. J. Reprod. Fert. 33, 145-149.

Mann, T. (1946) Studies on the metabolism of semen. 3. Fructose as a normal constituent of seminal plasma. Site of formation and function of fructose in semen. Biochem. J. 40, 481-491.

Marchalonis, J.J. (1969) An enzymatic method for the trace iodination of immunoglobulins and other proteins. Biochem. J. 113, 299-305.

Marchalonis, J.J., Cone, R.E. \& Santer, V. (1971) Enzymic iodination. A probe for accessible surface proteins of normal and neoplastic lymphocytes. Biochem. J. 124, 921-927.

Mersel, M., Benenson, A. \& Doljanski, F. (1976) Lactoperoxidase-catalyzed iodination of surface membrane lipids. Biochem. Biophys. Res. Commun. 70, 1166-1171.

Nicolson, G.L. \& Yanagimachi, R. (1972) Terminal saccharides on sperm plasma membranes: identification by specific agglutinins. Science, N.Y. 177, 276-279.

Nicolson, G.L. \& Yanagimachi, R. (1974) Mobility and restriction of mobility of plasma membrane lectinbinding components. Science, N.Y. 184, 1294-1296.

Nicolson, G.L., Usui, N., Yanagimachi, R., Yanagimachi, H. \& Smith, J.R. (1977) Lectinbinding sites on the plasma membranes of rabbit spermatozoa. Changes in surface receptors during epididymal maturation and after ejaculation. J. Cell Biol. 74, 950-962.

Olson, G.E. \& Hamilton, D.W. (1978) Characterization of the surface glycoproteins of rat spermatozoa. Biol. Reprod. 19, 26-35.

Phillips, D.W. \& Morrison, M. (1970) The arrangement of proteins in the human erythrocyte membrane. Biochem. Biophys. Res. Commun. 40, 284-289.

Salpeter, M.M., McHenry, F.A. \& Salpeter, E.E. (1978) Resolution in electron microscope autoradiography. IV. Application to analysis of autoradiographs. $J$. Cell Biol. 76, 127.

Voglmayr, J.K., Fairbanks, G., Jackowitz, M.A. \& Colella, J.R. (1979) Maturation changes in surface proteins of ram spermatozoa. Biol. Reprod. 20, 81A, Abstr.

Yanagimachi, R., Noda, Y.D., Fujimoto, M. \& Nicolson, G.L. (1972) The distribution of negative surface charges on mammalian spermatozoa. Am. J. Anat. 135, 497-520.

Yanagimachi, R., Nicolson, G.L., Noda, Y.D. \& Fujimoto, M. (1973) Electron microscopic observations of the distribution of acidic anionic residues on hamster spermatozoa and eggs before and during fertilization. J. Ultrastruct. Res. 43, 344-353.

Zahler, W.L. (1974) Analytical polyacrylamide gel electrophoresis and molecular weight determination. Meth. Enzymol. 32, 70-81. 